\title{
MANAJEMEN CEDERA AKIBAT OLAHRAGA PADA PELAJAR SMA DI KECAMATAN PRINGSURAT
}

\section{Injury Management Due To Sports in Senior High School Students District Of Pringsurat}

\author{
Mukhamad Musta'in ${ }^{1}$, Ika Nilawati ${ }^{2}$, Fredy Eko Setiawan ${ }^{2}$ \\ ${ }^{1}$ Prodi Diploma Tiga Keperawatan Fakultas Keperawatan Universitas Ngudi Waluyo Ungaran \\ ${ }^{2}$ Prodi S1 Ilmu Keolahragaan Fakultas Ilmu Kesehatan Universitas Ngudi Waluyo Ungaran \\ Email: mukhamadmustain@gmail.com
}

\begin{abstract}
Abstrak
Olahraga merupakan kegiatan yang sangat digemari oleh semua manusia dari berbagai usia, baik kalangan tua ataupuan muda. Masa SMA merupakan masa yang aktif dalam perkembangan kehidupannya. Banyak siswa SMA yang mengikuti kegiatan ekstrakurikuler olahraga seperti sepakbola, futsal, voli, baket dan lainnya. Kurangnya kehati- hatian saat berolahraga, para siswa sering mengalami suatu cedera. Pemberian informasi dan ketrampilan yang tepat tentang manajemen cedera melalui pelatihan manajemen cedera akut dan kronik dinilai sebagai salah satu upaya pencegahan atau meminimalkan kerusakan cedera lebih lanjut akibat olahraga. Tujuan kegiatan ini adalah peningkatan pengetahuan siswa tentang penanganan cedera pada fase akut atau kronik. Metode yang digunakan adalah melakukan skreening pengetahuan tentang manajemen cedera olahraga, selanjutnya pelaksanaan pelatihan manajemen cedera. Hasil dari kegiatan pengabdian ini adalah seluruh siswa mengikuti pelatihan manajemen cedera dan pemahaman siswa tentang penangan cedera sebelum pelatihan yaitu pengetahuan kurang (14\%), pengetahuan cukup (46\%) dan pengetahuan baik (40\%) dan saat posttest pengetahuan kurang $2 \%$, Cukup 20\% dan Baik 78\%. Dengan demikian dapat disimpulkan terdapat peningkatan pengetahuan peserta menjadi sebagian besar baik. Dengan demikian melalui pengabdian masyarakat para siswa diharapkan dapat melaksanakan upaya pencegahan cedera akibat olahrga dengan baik.
\end{abstract}

Kata kunci: Manajemen cedera, Olahraga, Siswa SMA

\section{Abstract}

Sport is an activity that is very popular with all people of various ages, both old and young. Senior high school is an active period in the development of his life. Many senior high school students take part in sports extracurricular activities such as soccer, futsal, volleyball, bucket and others. Lack of caution when exercising, students often experience an injury. Providing appropriate information and skills about injury management through acute and chronic injury management training is considered as an effort to prevent or minimize further injury damage due to sports. The purpose of this activity is to increase student knowledge about managing injuries in the acute or chronic phases. The method used is screening knowledge about sports injury management, then the implementation of injury management training. The results of this community service activity are all students participating in injury management training and students' understanding of injury management prior to training, namely lack of knowledge $(14 \%)$, sufficient knowledge $(46 \%)$ and good knowledge $(40 \%)$ and when posttest knowledge is less $2 \%$, Enough $20 \%$ and $78 \%$ Good. Thus it can be concluded there is an increase in the knowledge of participants to a large extent good. Thus through community service students are expected to carry out efforts to prevent injuries from sports well.

Keywords: Injury management, Sports, Senior high school students 


\section{PENDAHULUAN}

Olahraga merupakan kegiatan yang sangat digemari oleh semua manusia dari berbagai usia, baik kalangan tua ataupuan muda. Masa SMA merupakan masa yang aktif dalam perkembangan kehidupannya. Banyak pelajar SMA yang mengikuti kegiatan ekstrakurikuler olahraga seperti sepakbola, futsal, voli, baket dan lainnya. Kurangnya kehati- hatian saat berolahraga, para pelajar sering mengalami suatu cedera. Hasil penelitian Nugraha (2018) bahwa seorang atlit sepakbola yang bertanding mempunyai resiko cedera sebanyak $37,14 \%$. Cedera merupakan rusaknya struktur dan fungsi anatomis normal diakibatkan karena keadaan patologis (Potter\&Perry, 2005). Sedangkan menurut WHO (2016) cedera adalah kerusakan fisik yang terjadi ketika tubuh manusia tiba-tiba mengalami penurunan energy dalam jumlah yang melebihi ambang batas toleransi fisiologis atau akibat dari kurangnya satu atau lebih elemen penting seperti oksigen. Sukarmin (2005) menjelaskan bahwa, cedera olahraga dibedakan menjadi cedera lunak dan cedera jaringan keras. Cedera jaringan lunak adalah cedera pada otot, saraf, tendo, ligament, kulit, pembuluh darah. Sedangkan cedera jaringan keras adalah cedera pada tulang, berupa retak atau patah seluruhnya. Ada beberapa kemungkinan yang dapat terjadi saat terjadinya cedera, cacat fisik, ketidakmampuan menggerakan bagian tubuh yang cedera, kerugian ekonomi hingga meninggal dunia.

Usaha pencegahan dan perawatan cedera harus dilakukan secara terpadu dan berjalan simultan sesuai panduan pencegahan dan perawatan cedera, agar tidak menimbulkan resiko cedera yang lebih besar (Andrianto, 2016). Rendahnya pemahaman pelajar dalam penanganan cedera akan mempengaruhi lama penyembuhan cedera dan bahkan bisa menambah keparahan tingkat cedera.
Dengan pemberian pelatihan manajemen cedera akibat olahraga dan buku panduan penanganan cedera diharapkan mampu meningkatkan pengetahuan para pelajar SMA tentang perawatan cedera akibat olahraga dan meminimalkan kerusakan lebih lanjut akibat cedera.

Berdasarkan wawancara dengan guru/ pengajar olahraga di SMA N 1 Pringsurat menjelaskan, bahwa apabila ada siswa yang mengalami jatuh maka diberikan penanganan minimal berupa pemberian betadin atau minyak kayu putih dan disamping itu diruangan UKS belum tersedia buku panduan penanganan cedera akibat olahraga/ jatuh. Apabila kondisi terlihat parah maka dibawa ke puskesmas atau rumah sakit terdekat.

\section{TUJUAN}

Tujuan pelatihan ini adalah:

1. Tingginya partisipasi siswa dalam pelatihan manajemen cedera.

2. Peningkatan pengetahuan siswa dalam pelatihan manajemen cedera.

\section{PELAKSANAAN}

A. Sasaran dan Metode kegiatan yang digunakan.

Sasaran pengabdian adalah siswa Tim Palang Merah Remaja Wira SMA N 1 Pringsurat Kab Temanggung. Metode yang digunakan melalui penyuluhan tentang konsep cedera, pelatihan dan demostrasi manajemen cedera akut ataupun lanjut. Evaluasi dilakukan melalui pretest dan posttest dengan memberikan daftar pertanyaan/ kuesioner untuk mengetahui pengetahuan peserta dan redemonstrasi.

B. Waktu dan Tempat Kegiatan

Pengabdian masyarakat dilakukan di SMA N 1 Pringsurat Kab Temanggung pada tanggal 27 Januari 2020. Kegiatan di mulai jam 08.00 WIB hingga 11.00 WIB. Tempat kegiatan di Ruang Lab 
Fisika SMA N 1 Pringsurat Kab

Temanggung.

C. Materi

Materi yang disampaikan meliputi :

1. Cedera

2. Cedera akibat Olahrga

3. Manajemen cedera akut dan lanjut

\section{HASIL DAN PEMBAHASAN \\ HASIL}

Peserta pelatihan terdiri dari siswa kelas $\mathrm{X}$ yang merupakan Tim Palang Merah Remaja Wira SMA N 1 Pringsurat. Jumlah peserta yaitu 50 siswa baik lai- laki ataupun perempuan yang dapat dilihat pada tabel 1 berikut.

Tabel 1 Distribusi Frekuensi peserta pelatihan berdasar jenis kelamin

\begin{tabular}{clcc}
\hline No & $\begin{array}{c}\text { Jenis } \\
\text { Kelamin }\end{array}$ & Frek & $\begin{array}{c}\text { Prosentase } \\
(\%)\end{array}$ \\
\hline 1 & Laki- laki & 11 & $22 \%$ \\
2 & Perempuan & 39 & $78 \%$ \\
\hline & Total & 50 & $100 \%$ \\
\hline
\end{tabular}

Berdasarkan tabel 2 dapat disimpulkan bahwa peserta diikuti sebagian besar oleh perempuan. Hal ini menjelaskan bahwa ekstrakurikuler Palang Merah Remaja banyak digemari oleh anak perempuan. Kehadiran peserta mencapai $98 \%$ dari semua peserta yang diundang. Jumlah peserta berdasarkan kelas dapat dilihat pada tabel berikut:

Tabel 2 Distribusi Frekuensi peserta berdasarkan Peminatan Kelas

\begin{tabular}{clcc}
\hline No & $\begin{array}{c}\text { Peminatan } \\
\text { Kelas }\end{array}$ & Frekuensi & $\begin{array}{c}\text { Prosentase } \\
(\%)\end{array}$ \\
\hline 1 & IPA & 22 & $44 \%$ \\
2 & IPS & 20 & $40 \%$ \\
3 & IPB & 8 & $6 \%$ \\
\hline & Total & 50 & $100 \%$ \\
\hline
\end{tabular}

Berdasarkan tabel 2 dapat bahwa peserta kegiatan diikuti sebagian besar dari kelas IPA dan IPS. Kelas IPA dan IPS memang merupakan kelas yang banyak digemari oleh siswa SMA.

\begin{tabular}{cccc} 
Tabel 3. & $\begin{array}{l}\text { Distribusi Frekuensi } \\
\text { Berdasarkan } \\
\text { Pengetahuan } \\
\text { manajemen } \\
\text { olahraga sederta } \\
\text { (Pre-Test). }\end{array}$ & $\begin{array}{r}\text { Pedera } \\
\text { Tingkat } \\
\text { Tentang } \\
\text { akibat } \\
\text { pelatihan }\end{array}$ \\
$\begin{array}{clcc}\text { Tingkat } \\
\text { No }\end{array}$ & Frek & $\begin{array}{c}\text { Prosentase } \\
(\%)\end{array}$ \\
\hline & Pengetahuan \\
1 & Kurang & 7 & $14 \%$ \\
2 & Cukup & 23 & $46 \%$ \\
3 & Baik & 20 & $40 \%$ \\
\hline & Total & 50 & $100 \%$ \\
\hline
\end{tabular}

Berdasarkan tabel 3 bahwa sebagian besar dari responden $(46 \%)$ memiliki pengetahuan yang cukup tentang manajmen cedera pada saat sebelum pelatihan (pre-test). Hal ini Hal ini menunjukkan kemunginan peserta sudah sering terpapar materi tentang penanganan pertama pada kecelakaan/ trauma atau yang lain. Dimana hal ini mirip dengan penanganan cedera olahraga.

Tabel 4. Distribusi Frekuensi Peserta Berdasarkan Tingkat Pengetahuan Tentang Tempertantrum Setelah Pelatihan (Post-Test).

\begin{tabular}{clcc}
\hline No & $\begin{array}{c}\text { Tingkat } \\
\text { Pengetahuan }\end{array}$ & Frek & $\begin{array}{c}\text { Prosentase } \\
(\%)\end{array}$ \\
\hline 1 & Kurang & 1 & $2 \%$ \\
2 & Cukup & 10 & $20 \%$ \\
3 & Baik & 39 & $78 \%$ \\
\hline & Total & 50 & $100 \%$ \\
\hline
\end{tabular}

Berdasarkan tabel 5 bahwa sebagian besar dari responden (78\%) memiliki pengetahuan yang baik tentang manajemen cedera pada saat setelah dilakukan pelatihan (post-test).

\section{PEMBAHASAN}

Cedera adalah suatu gerakan yang berlebihan yang dilimpahkan pada tubuh 
dan tubuh tidak dapat menahan beban yang telah diterima sehingga berisiko cedera (Graha \& Priyonoadi, 2012 dalam Mukaromah, 2015). Hardiyanto (1995) juga menjelaskan bahwa cedera olahraga adalah segala macam cedera yang timbul, baik pada waktu latihan maupun pada waktu berolahraga (pertandingan) ataupun sesudah pertandingan, dimana area yang biasa terkena ialah tulang, otot, tendo, serta ligamen.

Tanda akut cedera olahraga yang umumnya terjadi adalah tanda respon peradangan tubuh berupa tumor ( pembengkakaan), kalor (peningkatan suhu), rubor (warna merah), dolor (nyeri) dan functioleissa (penurunan fungsi). Nyeri pertama kali muncul jika serat-serat otot atau tendon yang jumlahnya terbatas mulai mengalami robekan.Selain nyeri muncul tanda radang seperti bengkak, kemerahan, panas dan penurunan fungsi. Pada proses lanjut tandatanda peradangan tersebut akan berangsur angsur menghilang. Apabila tanda peradangan awal cukup hebat, biasanya rasa nyeri masih dirasakan samapai beberapa hari setelah onset cedera. Kelemahan fungsi berupa penurunan kekuatan dan keterbatasan jangakauan gerak juga sering dijumpai (Stevenson et al. 2000 dalam Arovah, 2009).

Penatalaksanaan cedera olahraga secara umum menggunakan prinsip RICE (Rest, Ice, Compression, Elevation) yang selalu diterapkan pada fase akut cedera sebelum penanganan selanjutnya. Indikasi RICE dilakukan pada cedera akut atau kronis eksaserbasi akut, seperti hematome (memar), sprain, strain, patah tulang tertutup, dislokasi setelah dilakukan reposisi. Secara umum penanganan cedera olahraga disesuaikan dengan jenis cedera dan proses patofisiologi cedera yang mendasari. Beberapa hal yang perlu diperhatikan untuk mencegah terjadinya cedera olahraga antara lain adalah perlu dilakukan kegiatan pemanasan dengan melibatkan latihan dinamis maupun statis dan perlu dilakukan pengaturan progresi latihan yang baik agar latihan dapat diadaptasi dengan baik oleh tubuh (Arovah, 2009).

Manajemen cedera yang baik tentu saja akan meminimalkan kerusakan cedera jaringan lebih lanjut. Berdasarkan hasil kajian pada tabel 3 ditemukan bahwa tingkat pengetahuan peserta sebelum pelatihan tentang manajemen cedera akibat olahraga sebanyak $46 \%$ siswa mempunyai pengetahuan cukup dan $40 \%$ mempunyai pengetahuan baik. Hal ini tidak terlepas dari keikutsertaan siswa dalam kegiatan ekstrakurikuler Palang Merah Remaja (PMR) yang sudah rutin dilakukan. Siswa mungkin sudah mendapat paparan tentang materi manajemen cedera akibat olahraga, hanya saja perlu diingatkan kembali (recall) materi tersebut. Hasil penelitian Prahesty dan Suwanda (2016) menunjukkan bahwa sikap tolong menolong siswa dapat dibentuk melalui beberapa kegiatan PMR, yaitu pertolongan pertama atau melakukan medis dasar pada siswa yang mengalami pusing, pingsan dan luka pada saat di sekolah.

Hasil evaluasi setelah pelatihan manajemen cedera berdasar tabel 4 dapat dilihat bahwa, tingkat pengetahuan peserta berada pada kategori kurang sejumlah $2 \%$, cukup sejumlah $20 \%$ dan baik sejumlah $78 \%$. Dengan demikian ada peningkatan pengetahuan setelah dilakukan pelatihan. Pengetahuan adalah hasil dari tahu yang terjadi setelah seseorang melakukan penginderaan terhadap suatu objek tertentu. Penginderaan terjadi melalui panca indera manusia, yakni indra penglihatan, pendengaran, penciuman, rasa dan raba, sebagian besar pengetahuan manusia diperoleh melalui mata dan telinga.

Pengetahuan merupakan dominan yang sangat penting untuk terbentuknya tindakan seseorang (Notoatmodjo, 2007). Menurut Azwar (1983) dalam Machfoedz (2007) dijelaskan bahwa penyuluhan 
merupakan pendidikan yang dilakukan dengan cara menyebarkan pesan, penanaman keyakinan sehingga masyarakat tidak hanya sadar, tahu dan mengerti, tetapi juga mau dan bisa melakukan suatu anjuran yang ada hubungannya dengan kesehatan. Mubarak (2007) menjelaskan informasi merupakan salah satu factor yang mempengaruhi pengetahuan karena kemudahan untuk memperoleh suatu informasi dapat membantu mempercepat seseorang untuk memperoleh pengetahuan yang baru.

Dalam penyampaian materi pelatihan, Tim menggunakan Liquor Crystal Dislyay (LCD) berupa power point yang sangat mendukung penyuluhan, dimana materi bisa dibuat menarik dan dapat menampilkan gambar sesuai aslinya sehingga peserta menjadi tidak mudah bosan. Disamping itu tim juga menyampaikan materi melalui demonstrasi seperti materi pembidaian cedera. Metode demonstrasi didefinisikan sebagai metode mengajar dengan menggunakan peragaan untuk memperjelas suatu pengertian atau untuk memperlihatkan bagaimana berjalannya atau bekerjanya suatu proses atau langkah-langkah kerja dari suatu alat atau instrumen tertentu kepada siswa. Dengan demonstrasi siswa akan lebih mudah mengingat langkah demi langkah dalam proses pembidaian cedera. Hasil Penelitian Situmorang dan Situmorang (2013) menjelaskan bahwa metode demonstrasi dapat meningkatkan hasil belajar siswa pada pengajaran siswa SMK, karena siswa dapat melihat secara langsung proses dan menjelaskan konsep. Perbedaan tingkat kemampuan penguasaan siswa disebabkan oleh metode penyampaian yang memberi kesan pembelajaran lebih lama diingat oleh siswa.

\section{DAFTAR PUSTAKA}

Arovah, NI. (2009). Diagnosis Dan Manajemen Cedera Olahraga. Dosen Jurusan Pendidikan Kesehatan dan Rekreasi FIK UNY. http://staff.uny.ac.id/sites/default/file s/132300162/12.\%20Diagnosis\%20d an\%20Manajemen\%20Cedera\%2001 ahraga.pdf

Andianto, SD. (2016). Pengembangan Aplikasi Panduan Pencegahan Dan Perawatan Cedera Untuk Olahraga Hiking (Smartpala) Berbasis Android Bagi Pecinta Alam Pemula. Jurnal Pendidikan Jasmani dan Rekreasi Kesehatan Vol V No 8 http://journal.student.uny.ac.id/ojs/oj s/index.php/pjkr/article/view/2759/2 $\underline{329}$

Hardianto, Wibowo. (1995). Pencegahan dan Penatalaksanaan Cidera Olahraga. Jakarta: Bina Rupa Aksara.

Machfoedz Ircham, dan Suryani Eko. (2007). Pendidikan Kesehatan Bagian dari Promosi Kesehatan. Yogyakarta. Fitramaya.

Mubarak. 2007. Promosi Kesehatan Sebuah Pengamatan Proses Belajar Mengajar dalam Pendidikan. Jokjakarta: Graha Ilmu.

Mukaromah, SB. 2015. Pengaruh Massage Frirage Terhadap Peningkatan Rom Pada Cedera Lutut. Journal of Sport Sciences and Fitness. Vol 4 No 4 hal 29-33.

http://journal.unnes.ac.id/sju/index.p hp/jssf/article/view/10094

Notoadmojo, S. (2007). Pendidikan dan Perilaku Kesehatan. Jakarta: PT Rineka Cipta

Nugraha, HEPA. (2018). Survei Cedera Olahraga Pada Atlet Sepak Bola Usia 13 Tahun Dalam Kompetisi Sepak Bola Piala Askab PSSI Kabupaten Nganjuk. SimkiTechsain Vol. 02 No. 02 Tahun 2018 
ISSN

3011 http://simki.unpkediri.ac.id/m ahasiswa/file_artikel/2018/7c02722a 74f56e1fb701503393b97fa9.pdf

Potter, P.A, Perry, A.G.2005. Buku Ajar Fundamental Keperawatan : Konsep, Proses, dan Praktik. Edisi 4. Volume 2. Alih Bahasa : Renata Komalasari,dkk. Jakarta: EGC.

Prahesty, RE dan Suwanda, IM. (2016). Peran Ekstrakurikuler Palang Merah Remaja Dalam Membentuk Sikap Tolong Menolong Siswa Di SMP $N$

Sidoarjo. Jurnal Kajian Moral dan Kewarganegaraan. Vol 01 No $04 \mathrm{Hal}$ 201-215.

https://jurnalmahasiswa.unesa.ac.id/i ndex.php/jurnal-pendidikankewarganegaraa/article/view/14301/ $\underline{4912}$

Situmorang, H dan Situmorang, M. (2013). Efektivitas Metode Demonstrasi Dalam Meningkatkan Hasil Belajar Siswa Sekolah Menengah Kejuruan Pada Pengajaran Sistem Koloid. Jurnal Penelitian Bidang Pendidikan
Volume $\quad$ 19(1): $28 \quad-36$. https://www.researchgate.net/profile/ Manihar_Situmorang/publication/32 4205680_Efektivitas_Metode_Demo nstrasi_Dalam_Meningkatkan_Hasil _Belajar_Siswa_Sekolah_Menengah _Kejuruan_Pada_Pengajaran_Sistem _Koloid/Links/5c3d14f1299bf12be3 c897fa/Efektivitas-MetodeDemonstrasi-Dalam-MeningkatkanHasil-Belajar-Siswa-SekolahMenengah-Kejuruan-PadaPengajaran-Sistem-Koloid.pdf

Sukarmin, Yustinus. 2005. Cedera Olahraga Dalam Prespektif Teori Model Ekologi. Jurnal Ilmu Keolahragaan MEDIKORA, Vol 1 No 1. https://journal.uny.ac.id/index.php/m edikora/article/view/4702/4050

World Health Organization (WHO). 2016. Media Centre. Physical Activity. (Online), http://www.who.int/mediacentre/fact sheets/fs385/en/, diakses 2 Februari 2020. 